\title{
PENENTUAN FORMULA PENAMBAHAN VOLUME AIR KONSTAN PADA PENGOMPOSAN SAMPAH DAUN
}

\author{
Ganjar Samudro, Sri Sumiyati, Mochtar Hadiwidodo, Dian Asri Puspa Ratna, \\ Sindi Martina Hastuti, Vaneza Citra Kurnia
}

\author{
Departemen Teknik Lingkungan, Fakultas Teknik, Universitas Diponegoro \\ JI. Prof. H. Soedarto, S.H. Tembalang-Semarang, Kode Pos 50275 \\ Telp : (024) 76480678, Fax : (024) 76918157 \\ E-mail: ganjarsamudro@gmail.com,ganjarsamudro@undip.ac.id
}

\begin{abstract}
ABSTRAK
Penambahan volume air pada pengomposan sampah daun masih dilakukan secara manual, membutuhkan waktu yang banyak, dan tenaga kerja yang besar. Tujuan penentuan ini dimaksudkan untuk mendapatkan formula penambahan volume air konstan pada pengomposan sampah daun secara kontinyu. Metode penelitian diawali dengan observasi penelitian hubungan waktu terhadap kadar air berdasarkan variasi kadar air yang diinginkan 50\% dan $60 \%$ sebagai kadar air optimum dalam proses pengomposan, kemudian dilanjutkan analisis kuantitatif deskriptif dalam penentuan formula. Formula penambahan volume air konstan pengomposan sampah daun sebagai berikut: debit input ( $\mathrm{mL} / \mathrm{L} / \mathrm{hari}): y=1,764 \mathrm{e}^{0,048 x}$, volume air $(m L / L): y=10,01 e^{0,049 x}$, dan volume air $(\%): y=-0,698 x+61,09$.
\end{abstract}

Kata kunci: formula, volume air konstan, pengomposan sampah daun

\begin{abstract}
The addition of the water volume in leaves litter is still manually done, takes time and a large workforce. This determination aim is to obtain the addition of the constant water volume formula in continuous leaves litter composting. The research method was began by the research observation of the relation of time to water content based on the desired water content variations of $50 \%$ and $60 \%$ as optimum water content in composting, then was continued by descriptive-quantitative analysis in formula determination. The addition of the constant water volume formula as follow: input flow rate $(\mathrm{mL} / \mathrm{L} / \mathrm{d}): y=1,764 \mathrm{e}^{0,048 x}$, water volume $(\mathrm{mL} / \mathrm{L}): y=$ $10,01 e^{0,049 x}$, dan water volume $(\%): y=-0,698 x+61,09$.
\end{abstract}

Keywords: formula, the constant water volume, leaves litter composting

\section{PENDAHULUAN}

Salah satu kesulitan operasional dalam pengomposan sampah daun adalah penambahan volume air. Penambahan volume air selalu dilakukan secara manual per hari dan umumnya tanpa melihat kadar air selama proses pengomposan. Formula penambahan volume air secara manual dengan ketelitian hingga 99\%, telah diusulkan oleh Ministry of Agriculture and Food (1998). Namun formula penambahan volume air konstan yang mengacu pada penambahan air secara kontinyu belum ditemukan. Penambahan volume air konstan dapat memudahkan operasional pengomposan secara kontinyu dan dapat diamati secara real time. Pada praktiknya, air dapat ditambahkan menggunakan flow meter untuk menentukan jumlah air yang dibutuhkan dan untuk menjaga kadar air pada range yang ditetapkan (EstévezSchwarz dkk, 2012). Oleh karena itu formula penambahan volume air konstan diperlukan untuk mendapatkan penambahan volume air konstan pada pengomposan sampah daun secara kontinyu.

Penambahan volume air konstan telah didapatkan oleh Samudro dkk (2017), dimana penambahan volume air konstan dengan kadar air yang diinginkan 50\% sebesar $334 \mathrm{~mL} / \mathrm{kg}$ sampah/siklus $\approx 100$ $\mathrm{mL} / \mathrm{L}$ sampah/siklus $\approx 24 \%$ penambahan volume air $\approx 17 \mathrm{~mL} /$ hari debit input. Sedangkan penambahan volume air konstan dengan kadar air yang diinginkan $60 \%$ sebesar $717 \mathrm{~mL} / \mathrm{kg}$ sampah/siklus $\approx$ $215 \mathrm{~mL} / \mathrm{L}$ sampah/siklus $\approx 16 \%$ penambahan volume air $\approx 36 \mathrm{~mL} /$ hari debit input. Berdasarkan besaran kadar air yang diinginkan tersebut, maka formula penambahan volume air konstan didapatkan dari hubungan volume sampah sebagai axis dengan volume dan debit air konstan sebagai absis, serta prosentase 
penambahan volume air sebagai kapasitas tampung air.

\section{METODOLOGI}

Formula penambahan volume air konstan dilakukan dengan metode:

1. Kajian data sekunder berupa hasil penambahan volume air konstan oleh Samudro dkk (2017). Berdasarkan kajian data sekunder tersebut didapatkan ekuivalensi dalam 1 siklus pengomposan yang terdiri dari $1 \mathrm{~kg}$ massa sampah, penambahan volume air, prosentase penambahan volume air air dan debit input.

2. Kadar air yang diinginkan sebesar $50 \%$ dan $60 \%$ merupakan dasar penentuan formula. Pemilihan kadar air yang diinginkan $50 \%$ dan $60 \%$ berdasarkan pada kadar air optimum dalam proses pengomposan sampah daun dengan ukuran bahan $1 \mathrm{~cm}$ (Dian dkk, 2017; Sindi dkk, 2017; Vaneza dkk, 2017).

3. Penentuan formula berdasarkan ekuivalensi dan verifikasi menggunakan bantuan program MS Excel. Program MS Excel memberikan perhitungan $R^{2}$ untuk setiap model yang kita bangun. Karenanya kita bisa menggunakan ukuran $\mathrm{R}^{2}$ ini untuk memilih model trend yang terbaik. Secara umum, model trend terbaik adalah model dengan nilai $\mathrm{R}^{2}$ yang paling tinggi (Junaidi, 2015). Junaidi (2015) menyatakan bahwa terdapat berbagai pola pergerakan data deret waktu, antara lain Model Linear, Model Quadratic, Model Exponential Growth, Model S-Curve (Pearl-Reed Logistic), Model Moving Average, Model Single Exponential Smoothing, Model Double Exponential Smoothing, Metode Winter, dan Model ARIMA. Pengamatan terhadap pola pergerakan data pada periode-periode sebelumnya, maka dapat dipilih pola yang tepat yang dijadikan sebagai dasar peramalan (Junaidi, 2014). Penentuan formula ditentukan menggunakan analisis regresi linier sederhana, eksponensial dan logaritmik. Dari ketiga analisis tersebut dipilih nilai $R^{2}$ yang paling tinggi. Analisis regresi merupakan suatu cara yang dapat digunakan untuk mengetahui hubungan sebuah variabel tak bebas (regressand) dengan sebuah atau lebih variabel bebas (regressor) (Rahmadeni dan Anggreni, 2014).
Trend linear adalah kecenderungan data dimana perubahannya berdasarkan waktu adalah tetap (konstan). Titik-titik data tidak akan persis seluruhnya melewati garis lurus, tetapi secara umum, pola yang terlihat akan membentuk seperti garis lurus (Junaidi, 2014). Sedangkan trend pertumbuhan eksponensial adalah kecenderungan data dimana perubahannya semakin lama semakin bertambah secara eksponensial (Junaidi, 2014). Pada model eksponensial terjadi peningkatan dalam semivariogram yang sangat curam dan mencapai nilai sill secara asimtotik (Laksana, 2010).

\section{HASIL DAN PEMBAHASAN}

Penentuan penambahan volume air konstan oleh Samudro dkk (2017) merupakan dasar rancangan formula penambahan volume air konstan pada pengomposan sampah daun secara kontinyu.

1. Ekuivalensi penambahan volume air pada kadar air pengomposan $50 \%$ :

- 1 siklus pengomposan = $1 \mathrm{~kg}$ massa sampah $=334 \mathrm{~mL}$ penambahan volume air $=24 \%$ penambahan volume air $=17$ $\mathrm{mL} /$ hari

- 1 siklus pengomposan $=1$ Liter volume sampah $=100 \mathrm{~mL}$ penambahan volume air $=24 \%$ penambahan volume air $=17$ $\mathrm{mL} /$ hari

2. Ekuivalensi penambahan volume air pada kadar air pengomposan $60 \%$ :

- 1 siklus pengomposan = $1 \mathrm{~kg}$ massa sampah $=717 \mathrm{~mL}$ penambahan volume air $=16 \%$ penambahan volume air $=36$ $\mathrm{mL} /$ hari.

- 1 siklus pengomposan = 1 Liter volume sampah = $215 \mathrm{~mL}$ penambahan volume air $=16 \%$ penambahan volume air $=36$ $\mathrm{mL} /$ hari.

Berdasarkan ekuivalensi penambahan volume air pada kadar air pengomposan $50 \%$ dan $60 \%$, maka dapat diprediksi volume air pada kadar air pengomposan dibawah $50 \%$ dan $60 \%$. 


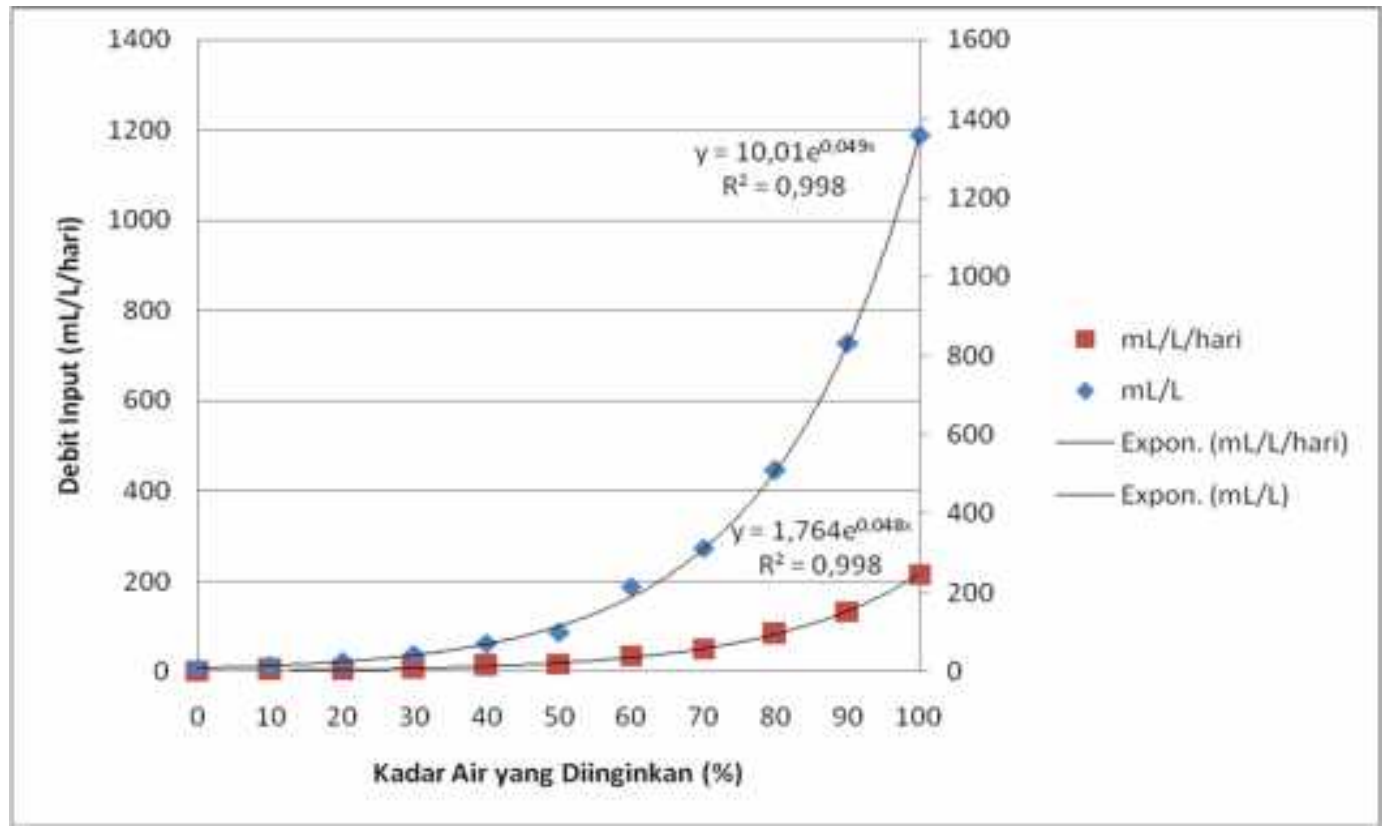

Gambar 1. Simulasi Terkoreksi Volume Air dan Debit Air pada Setiap Volume Sampah

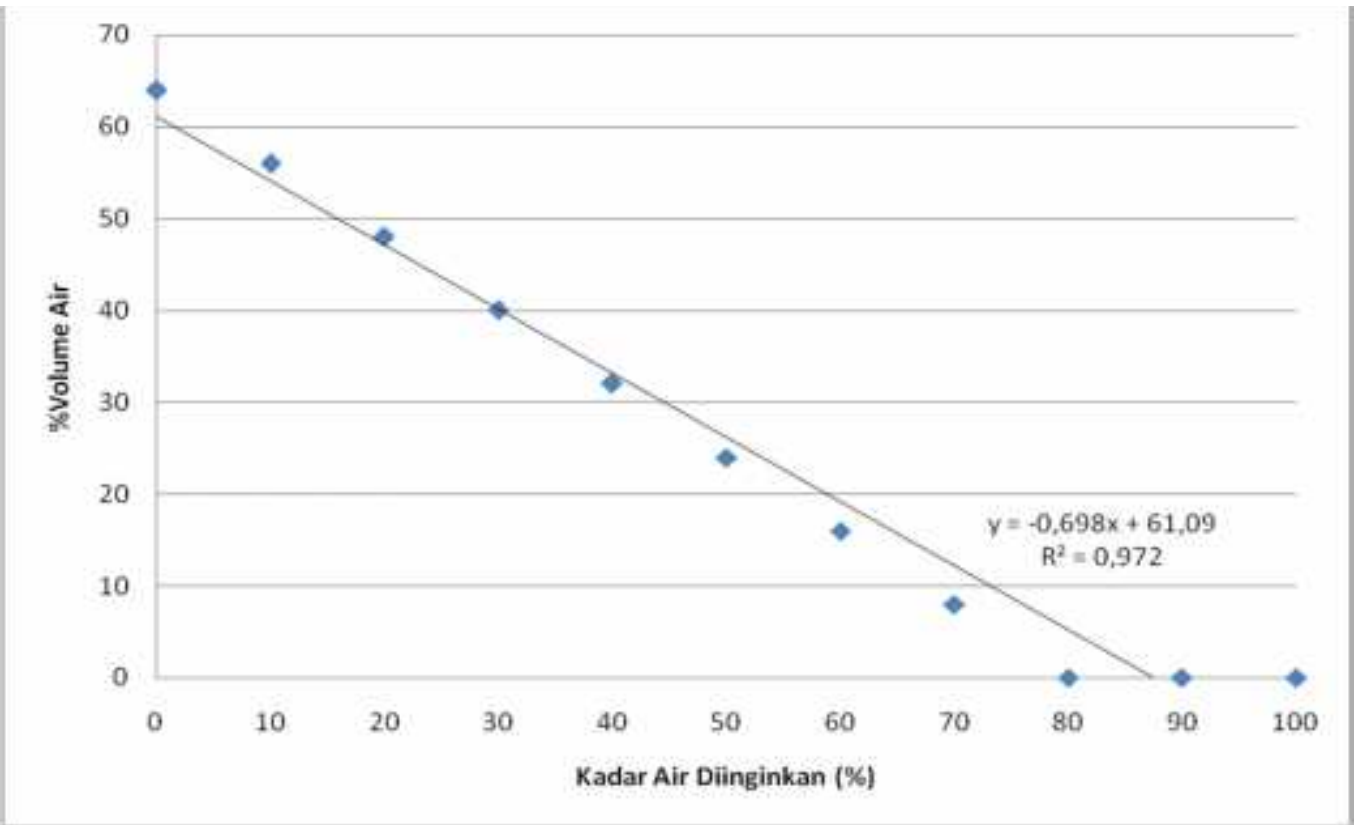

Gambar 2. Simulasi Terkoreksi \%Volume Air pada Setiap Volume Sampah

Gambar 1 menyatakan hubungan kadar air yang diinginkan (\%) dengan debit input ( $\mathrm{mL} / \mathrm{L} /$ hari) dan volume air $(\mathrm{mL} / \mathrm{L})$. Debit input dapat dinyatakan volume air yang ditambahkan per hari dalam 1 liter volume sampah. Debit input sebanding dengan volume air yang ditambahkan dalam 1 liter volume sampah. Formula kadar air yang diinginkan terhadap debit input dan volume air membentuk model pertumbuhan eksponensial sebagai berikut:
Debit input: $y=1,764 e^{0,048 x}$ dimana:

y $\quad$ : Debit input ( $\mathrm{mL} /$ Lsampah/hari)

$x \quad$ : Kadar air yang diinginkan (\%)

e $: 2,71828$

Volume air: $y=10,01 e^{0,049 x}$ dimana:
y $\quad$ : Volume air ( $\mathrm{mL} /$ Lsampah)
$\mathrm{x} \quad$ : Kadar air yang diinginkan (\%)
e $: 2,71828$ 
Gambar 2 menyatakan hubungan kadar air yang diinginkan (\%) dengan volume air (\%). Semakin besar kadar air yang diinginkan, maka semakin kecil volume air (\%). Volume air dalam satuan persentase merupakan kapasitas tampung air dalam 1 siklus pengomposan. Semakin kecil volume air (\%) dapat diartikan semakin besar volume air yang ditambahkan per hari per volume sampah. Formula kadar air yang diinginkan terhadap persentase volume air membentuk model regresi linier sederhana sebagai berikut:

Volume air: $y=-0,698 x+61,09$

dimana:

y $\quad$ : Volume air (\%)

$\mathrm{x} \quad$ : Kadar air yang diinginkan (\%)

\section{KESIMPULAN}

Formula penambahan volume air konstan debit input $(\mathrm{mL} / \mathrm{L} /$ hari): $y=$ $1,764 \mathrm{e}^{0,048 \mathrm{x}}$, volume air $(\mathrm{mL} / \mathrm{L}): \mathrm{y}=$ $10,01 e^{0,049 x}$, dan volume air (\%):y $=-0,698 x$ $+61,09$.

\section{UCAPAN TERIMA KASIH}

Ucapan terima kasih disampaikan kepada Saudari Dian Asri Puspa Ratna, Sindi Martina Hastuti dan Vaneza Citra Kurnia sebagai mahasiswa Tugas Akhir ang membantu dalam penelitian dan Departemen Teknik Lingkungan FT UNDIP, serta Laboratorium Teknik Lingkungan FT UNDIP.

\section{DAFTAR PUSTAKA}

Dian Asri Puspa Ratna, Ganjar Samudro, Sri Sumiyati, (2017), Pengaruh Kadar Air Terhadap Proses Pengomposan Sampah Organik dengan Metode Takakura, Universitas Mercubuana, DKI Jakarta, Seminar Nasional Pengkajian dan Penerapan Teknologi.

Estévez-Schwarz I., Seoane-Labandeira S., Núñez-Delgado A., LópezMosquera M.E., (2012), Production and Characterization of Compost Made from Garden and Other Waste, Pol. J. Environ. Stud. Vol. 21 , No. 4 , pp. $855-864$.
Ganjar Samudro, Sri Sumiyati, Dian Asri Puspa Ratna, Sindi Martina Hastuti dan Vaneza Citra Kurnia, (2017), Penentuan Penambahan Volume Air Konstan pada Pengomposan Sampah Daun menggunakan Pendekatan Grafis Reservoir, Jurnal Sains \& Teknologi, Vol. 9 No.1.

Junaidi, (2014), Analisis Hubungan Deret Waktu untuk Peramalan, Fakultas Ekonomi dan Bisnis Universitas Jambi.

Junaidi, (2015), Estimasi, Pemilihan Model dan Peramalan Deret Waktu dengan Microsoft Office Excel, Fakultas Ekonomi dan Bisnis Universitas Jambi.

Laksana, EA., (2010), Analisis Data Geostatistika Dengan Universal Kriging, Skripsi Fakultas Matematika dan IImu Pengetahuan Alam Universitas Negeri Yogyakarta.

Ministry of Agriculture and Food, (1998), Composting Factsheet $-B C$ Agricultural Composting Handbook (Second Edition 2nd Printing), Canada, BC Ministry of Agriculture, Food and Fisheries.

Rahmadeni dan Defi Anggreni, (2014), Analisis Jumlah Tenaga Kerja Terhadap Jumlah Pasien RSUD Arifin Achmad Pekanbaru Menggunakan Metode Regresi Gulud. Jurnal Sains, Teknologi dan Industri, Vol. 12, No. 1 , pp. $48-$ 57.

Sindi Martina Hastuti, Ganjar Samudro, Sri Sumiyati, (2017), Pengaruh Kadar Air terhadap Hasil Pengomposan Sampah Organik dengan Metode Composter Tub, Universitas Mercubuana, DKI Jakarta, Seminar Nasional Pengkajian dan Penerapan Teknologi.

Vaneza Citra Kurnia, Ganjar Samudro, Sri Sumiyati, (2017), Pengaruh Kadar Air terhadap Hasil Pengomposan Sampah Organik dengan Metode Open Windrow, Universitas Mercubuana, DKI Jakarta, Seminar Nasional Pengkajian dan Penerapan Teknologi. 